\title{
Regulation of Differentiation of HC11 Mouse Breast Epithelial Cells by the Signal Transducer and Activator of Transcription-3
}

\author{
MAXIMILLIAN NIIT ${ }^{1 *}$, MULU GELETU ${ }^{2 *}$, ZAID TAHA ${ }^{1,3}$, ROZANNE ARULANANDAM $^{3}$, \\ JAMAICA CASS ${ }^{1}$, VICTORIA HOSKIN ${ }^{1}$, BRUCE ELLIOTT ${ }^{1}$, PATRICK GUNNING ${ }^{3}$ and LEDA RAPTIS $^{1}$ \\ ${ }^{1}$ Department of Biomedical and Molecular Sciences and Department of Pathology and Molecular Medicine, \\ Queen's University, Kingston, ON, Canada; \\ ${ }^{2}$ Department of Chemical and Physical Sciences, University of Toronto, Mississauga, ON, Canada; \\ ${ }^{3}$ Center for Innovative Cancer Research, Ottawa Hospital Research Institute, Ottawa, ON, Canada
}

\begin{abstract}
Background/Aim: The differentiation of the mouse breast epithelial cell line HC11 is known to require confluence as well as the addition of hydrocortisone, insulin and prolactin. Materials and Methods: Since confluence, which triggers the engagement of the cell-to-cell adhesion molecule E-cadherin, induces a dramatic increase in the activity of signal transducer and activator of transcription-3 (Stat3), we examined the role of Stat 3 in HC11 cell differentiation. Results: Stat3 inhibition abolished differentiation, indicating that Stat 3 activity is critically required. However, expression of the mutationally activated form of Stat3 (Stat3C), rather than promoting, it was found to block cell differentiation, even when expressed in low levels, and in the absence of full neoplastic conversion. Conclusion: The strength of the $E$ cadherin/Stat3 signal is key for the outcome of the differentiation process.
\end{abstract}

The mammary gland provides a useful model to study epithelial cell differentiation. The HC11 line, which was derived from mouse breast at mid-gestation, has been used extensively in differentiation studies because it behaves like the normal mammary epithelium (1), in that it can differentiate and produce milk proteins in response to lactogenic stimulation at confluence (2).

The signal transducer and activator of transcription-3 (Stat3) is activated by receptor and non-receptor tyrosine kinases, and

*These Authors contributed equally to this study.

Correspondence to: Mulu Geletu, Department of Chemical and Physical Sciences, University of Toronto, 3359 Mississauga Rd, Building DV3020B, Mississauga, ON L5L 1C6, Canada. Tel: +1 9055694588, Mobile: +19058081780, e-mail: mulu.geletu@ utoronto.ca

Key Words: E-cadherin, Stat3, cell differentiation. cytokines, such as members of the IL6 family (3). Stat3 activation involves its binding to phosphotyrosine (ptyr) sites of activated receptors through its $\mathrm{SH} 2$ domain. Stat 3 is subsequently phosphorylated at a critical phosphotyrosine (tyr705) by the receptor itself or associated Jak or Src kinases, dimerizes through reciprocal SH2-ptyr interaction and migrates to the nucleus, where it binds to target sequences on the DNA (4). This leads to the transcriptional activation of specific genes promoting survival, such as $M c l-1, B c l-x L$ or survivin, or proliferation, such as $m y c$ and $c y c l i n D$ and others (4). Stat3 is found to be overactivated in a number of cancers $(5,6)$, and is required for transformation by a number of oncogenes, such as Src (7) and the Simian virus 40 large tumor antigen (8), while in an activated form (Stat3C), Stat3 is able to transform cultured cells and induce tumors in nude mice. The latter points to an etiologic role for Stat3 in cancer (9).

In addition to this mechanism, results from our lab and others have demonstrated that engagement of cadherins, as induced by confluence of cultured cells, triggers a striking increase in Stat3 activity $(10,11)$, through the Rac and Cdc42, small GTPases $(10,12)$. In fact, it has been shown that cadherin engagement per se can directly increase Rac and Stat 3 activity, even in the absence of cell to cell contact, as shown by the fact that growing cells on surfaces coated with E-cadherin (10) or cadherin-11 (11) causes a dramatic increase in Stat3 activity.

Since confluence-induced growth arrest is an established prerequisite for $\mathrm{HC} 11$ cell differentiation, we recently examined the role of Rac. The results demonstrated that cRac1 is critically required for $\mathrm{HC} 11$ differentiation, and that expression of low levels of a mutationally activated form of cRac1 ( $\operatorname{Rac}^{\mathrm{V} 12}$ ) actually increased differentiation (13). Since Stat3 is an effector of Rac, in the present communication we examined the role of Stat3 upon HC11 differentiation. Interestingly, our results indicate that, despite the fact that Stat 3 was also required for the differentiation of $\mathrm{HC} 11$ cells, in a manner similar to $\mathrm{CRac} 1$, mutationally activated Stat3C 
was found to block differentiation, even when expressed at low levels. Therefore, although Stat 3 operates in the same pathway emanating from E-cadherin and is a downstream target of Rac, in an activated form induced by mutation, unlike $\mathrm{Rac}^{\mathrm{V} 12}$, Stat3C does not promote differentiation.

\section{Materials and Methods}

Cell culture and differentiation induction. HC11 cells differentiate and produce $\beta$-casein, a major milk protein, when they are treated with hydrocortisone, insulin and prolactin (HIP medium) at confluence in a medium lacking EGF, a differentiation inhibitor. HC11 cells were grown in RPMI-1640 medium with $10 \%$ fetal bovine serum, $5 \mu \mathrm{g} / \mathrm{ml}$ insulin (Sigma, MO, USA, Cat. \#91077C) and $10 \mathrm{ng} / \mathrm{ml}$ epidermal growth factor (EGF; Sigma \#E9644). For differentiation induction, at $100 \%$ confluence, cells were grown for $24 \mathrm{~h}$ in the same medium but lacking EGF (day 0), followed by growth in HIP medium $[1 \mu \mathrm{g} / \mathrm{ml}$ hydrocortisone (Sigma, Cat. \#H0888), $5 \mu \mathrm{g} / \mathrm{ml}$ insulin and $5 \mu \mathrm{g} / \mathrm{ml}$ prolactin (Sigma Cat. \#L6520) in RPMI-1640 with $10 \%$ fetal calf serum, without added EGF] for up to 10 days, as described in (13). Cells grown to the same densities and EGF-starved but not treated with HIP served as negative controls. To make sure that the cells were not starved from nutrients, HIP medium was changed every two days.

For Stat 3 inhibition, cells were treated with low levels $(1 \mu \mathrm{M})$ of the CPA7 Stat3 inhibitor [inhibition $15 \pm 5 \%$ (13-15)], or $5 \mu \mathrm{M}$ SH454 [inhibition $20 \%$ (15-17)], or $100 \mu \mathrm{M}$ S3I-201 [inhibition $20 \%$ $(18,19)]$. All inhibitors were added at the time of EGF starvation (day 0 ) for $24 \mathrm{~h}$, followed by HIP medium addition in the absence of inhibitor, and cells were allowed to differentiate for 10 days thereafter as above.

Retroviral vectors. The retroviral MSCV-Stat3C vector, which contains an internal ribosome entry site (IRES) linked to green fluorescence protein (GFP), was a gift from Dr. Daniel Link (20). The EF.Stat3C.Ubc.GFP lentiviral vector was a gift from Dr. Linzhao Chang (Addgene Cat. \#24983 MA, USA) (21).

Expression was measured by Western blotting for total Stat 3 and by transcriptional activity, using $\mathrm{HC} 11$ cells expressing high Stat 3 levels using the MSCV-Stat3C vector [line HC11-Stat3C (10)] as a positive control.

Cell lysis and western blotting. Cells were scraped from the petri dishes into an $1.8 \mathrm{ml}$ Eppendorf tube, washed with cold PBS by centrifugation and lysed with $1 \%$ NP-40 buffer containing protease and phosphatase inhibitors as previously described (22). Gels were probed for Stat3-ptyr705 (Cell Signalling Technology, MA, USA, rabbit monoclonal antibody D3A7, Cat. \#9145), total Stat3 (Cell Signalling Technology, rabbit monoclonal antibody 79D7, Cat. \#4904), $\beta$-casein (goat, Santa Cruz Biotech, TX, USA Cat. \#sc17971), E-cadherin (mouse, Invitrogen, CA, USA, Cat. \#33-400), or $\beta$-actin (mouse monoclonal, Cell-signaling technology Cat. \#3700) as a loading control. Luciferase assays were performed on total cell extracts as previously described $(10,23)$.

Anchorage-independence assays. They were performed as described (13), with HC11 cells expressing high Stat3C levels [line HC11Stat3C (10)] as a positive control. Trypsinised cells were suspended in $0.3 \%$ low melting point agarose for 20 days at $37^{\circ} \mathrm{C} / 5 \% \mathrm{CO}_{2}$. At

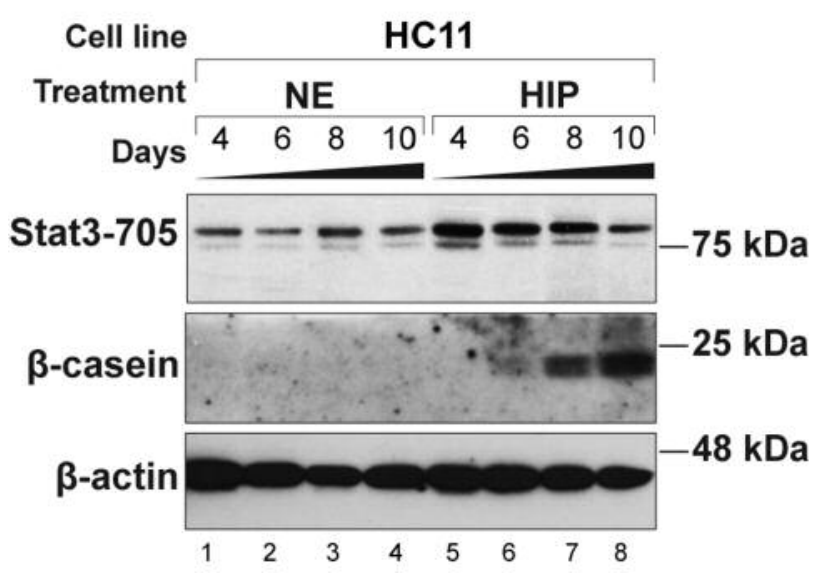

Figure 1. Differentiation of HC11 cells increases Stat3-ptyr705 levels. After reaching confluence in complete medium, HC11 cells were grown in the absence of EGF for $24 \mathrm{~h}$, then they were induced to differentiate with HIP addition for the indicated number of days (lanes 5-8), or not (lanes 1-4). Detergent cell extracts were probed for Stat3-ptyr705, $\beta$ casein or $\beta$-actin as a loading control, as indicated. NE: Control cultures, grown in the absence of EGF, but not induced to differentiate. Numbers at the right refer to molecular weight markers.

that time, cells were photographed under phase-contrast illumination using an Olympus IX70 microscope (Olympus Corporation, Tokyo, Japan). For quantitation, colonies were stained with $0.05 \%$ crystal violet (Sigma Cat. \#C3886) dissolved in 20\% methanol and were counted on photographs of cells at $140 \times$ magnification. Anchorageindependent growth was expressed as a percentage of total cell count. All experiments were performed at least three times with 3 , $3 \mathrm{~cm}$ petris per line, counting at least 200 cells from each petri in different fields.

\section{Results}

Differentiation increases Stat3-ptyr705 levels. We and others have previously demonstrated that cadherin engagement, as occurs in confluent cultured cells, triggers a dramatic increase in Stat3-ptyr705 expression and activity in a variety of cellular systems, including HC11 [(10) reviewed in $(24,25)]$. Since cell density is a prerequisite for the differentiation of $\mathrm{HC} 11$ cells, we now examined the effect of differentiation per se upon Stat3-ptyr705 levels. HC11 cells were grown and induced to differentiate, as described in Materials and Methods.

As previously demonstrated (10) cell density from $50 \%$ of confluence to 2 days post $100 \%$ confluence causes a dramatic increase in Stat3-ptyr705. However, as shown in Figure 1, HIP addition to cells grown to $100 \%$ confluence caused an approximately 2-fold increase in Stat3-ptyr705 levels, compared to EGF-starved, non-HIP-treated cells, indicating that HIP addition, and possibly differentiation, causes an increase in Stat3-ptyr705. As expected, probing for 
A

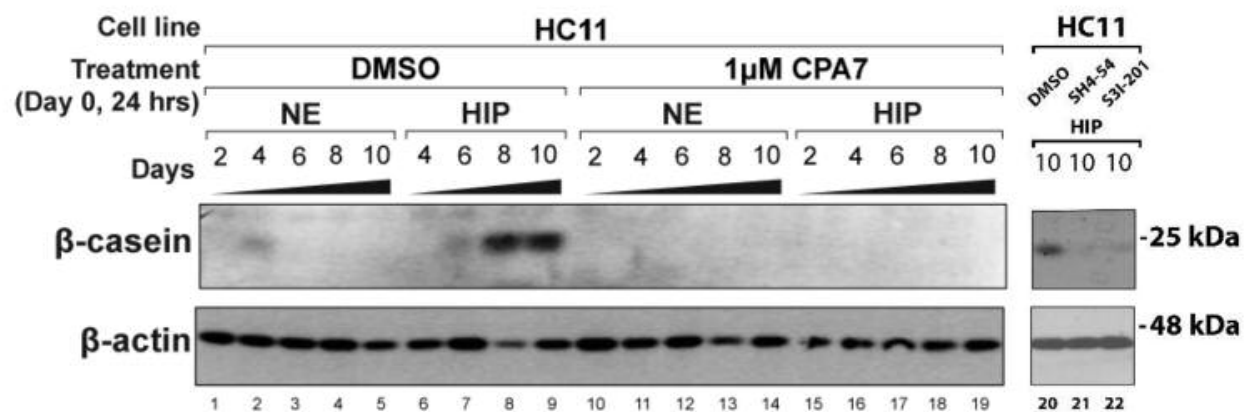

B

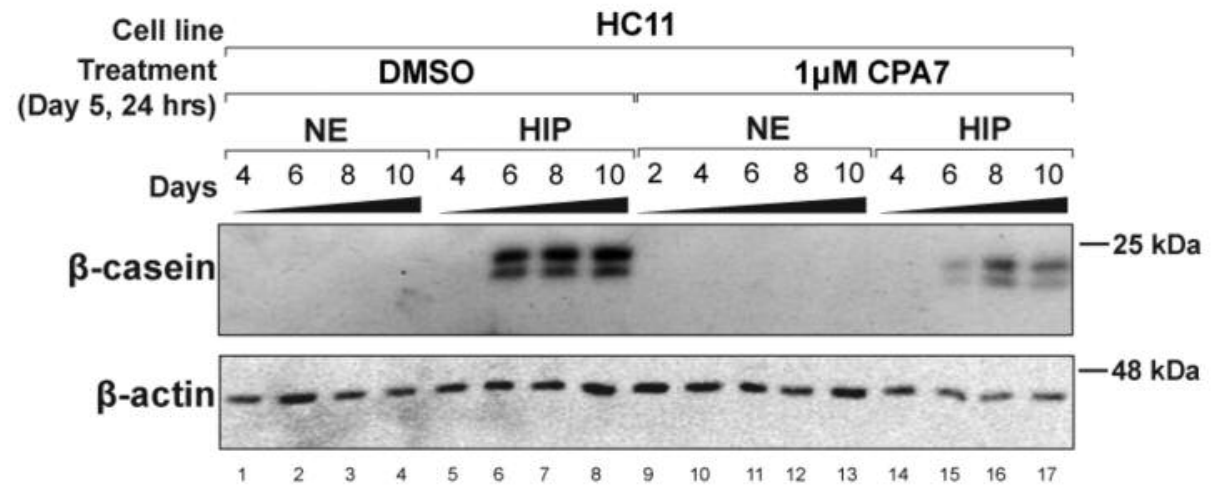

Figure 2. (A) Stat 3 inhibition with $1 \mu M$ CPA7 on day 0 prior to induction of differentiation completely blocks differentiation of HC11 cells. HC11 cells were grown in the absence of EGF for 24 hours, then induced to differentiate with HIP medium addition for the indicated number of days (lanes 6-9 and 15-19), or not (lanes 1-5 and 10-14). Cells were treated with $1 \mu M$ CPA7, Stat3 inhibitor (lanes 10-19) for 24 h prior to HIP addition, or the DMSO carrier (lanes 1-9). Detergent cell extracts were probed for $\beta$-casein or $\beta$-actin as a loading control, as indicated. NE: Control cultures, grown in the absence of EGF, but not induced to differentiate. Note the dramatic reduction in $\beta$-casein levels upon CPA7 treatment. Lanes 20-22: Stat3 inhibition with $5 \mu$ M SH4-54 or $100 \mu$ M S3I-201 on day 0 prior to induction of differentiation blocks differentiation of HC11 cells. Cells were grown in the absence of EGF then induced to differentiate as above. Cells were treated with $5 \mu$ M SH4-54 (lane 21) or 100 $\mu$ M S3I-201 (lane 22) for $24 \mathrm{hrs}$ prior to HIP addition and 10 days later lysates were probed for $\beta$-casein or $\beta$-actin, as indicated. Note the reduction in $\beta$-casein levels upon treatment with the inhibitors (lanes 21,22), compared to untreated control (DMSO carrier, lane 20). Numbers at the right refer to molecular weight markers. (C) Stat 3 inhibition with $1 \mu M$ CPA7 on day 5 following differentiation induction only partially reduces differentiation of HC11 cells. HC11 cells were grown in the absence of EGF for 24 hours, then they were induced to differentiate with HIP addition for the indicated number of days (lanes 5-8 and 14-17), or not (lanes 1-4 and 9-13). Cells were treated with $1 \mu M$ CPA7, Stat3 inhibitor (lanes 9-17) for 24 h on day 5 following HIP addition, or not (lanes 1-8). Detergent cell extracts were probed for $\beta$-casein or $\beta$-actin as a loading control, as indicated. $N E$ : Control cultures, grown in the absence of EGF, but not induced to differentiate. Numbers at the right refer to molecular weight markers. Note the relatively small reduction in $\beta$-casein upon CPA7 treatment on day 5 compared to day 0 in Figure $2 A$, above.

casein showed high levels of this protein upon HIP treatment, while it was undetectable in untreated controls (lanes 3-4 versus 7-8).

Stat3 is required for HC11 cell differentiation. Since Stat3ptyr705 levels are increased with HC11 cell differentiation, we examined whether Stat3 activity might, in fact, be required for differentiation. Three Stat 3 inhibitors (CPA7, SH4-54, S3I-201) were employed at low levels, as to induce an inhibition of $15-20 \%$ (see Materials and Methods). As shown in Figure 2A, Stat 3 inhibition using CPA7 eliminated differentiation, as revealed by $\beta$-casein levels (lanes 1-19).
Similar results were obtained with the SH4-54 (lane 21) and S3I-201 (lane 22) inhibitors, in agreement with previous data (18). Together with the demonstration that E-cadherin is required for $\mathrm{HC} 11$ differentiation (13), these findings point to the possibility that Stat 3 is transducing the differentiation signal emanating from E-cadherin in this system.

As shown in Figure 1, a slight decrease in Stat3-ptyr705 levels was consistently observed during days 6-10 post differentiation induction. To examine the requirement for Stat 3 at later times along the differentiation process, CPA7 was added on day 5 following differentiation induction. As shown in Figure 2B, CPA7 addition on day 5 could reduce 
but not eliminate casein levels, compared to its addition at the beginning of the differentiation process (Figure 2A, lanes 1-19), while addition on day 7 or beyond had no effect. These data strongly suggest that Stat 3 activity is needed specifically during the early stages of differentiation, while it may be dispensable once the differentiation process is underway.

Constitutively active Stat3C inhibits HC11 cell differentiation in the absence of full neoplastic transformation. Since Stat3 is required for, and is up-regulated during breast epithelial cell differentiation, it might be expected that its constitutively active mutant, Stat3C, would reinforce or potentiate the Stat3-mediated differentiation signal. To examine the effect of Stat $3 \mathrm{C}$, the latter was stably expressed with a retroviral vector [clones MSCV-Stat3C-a and -b (20), Figure 3A]. Interestingly, Stat3C, when expressed to levels similar to the endogenous Stat 3 in clones MSCV-Stat3C-a and $-b$, it was able to eliminate differentiation of $\mathrm{HC} 11$ cells (Figure 3A).

To further verify the effect of Stat3C on HC11 differentiation, Stat3C was expressed using a lentiviral vector and clones expressing very low Stat 3 levels $(\sim 15 \%$ Stat 3 transcriptional activity compared to the control HC11Stat3C, clones lenti-Stat3C-c and -d) were chosen for further analysis. As shown in Figure 3B, differentiation was reduced, although not eliminated. Taken together, the above data reveal an inverse, quantitative relationship between differentiation and Stat3 activity levels (Figure 3C). Unlike mutationally activated, $\mathrm{Rac}^{\mathrm{V} 12}$, which at low levels could increase differentiation, no increase in differentiation was ever observed in the Stat3C-expressing clones examined, as it would have been expected in the case where Stat3C potentiated the E-cadherin-mediated differentiation signal.

To examine whether the inability of Stat3C-expressing HC11 cells to differentiate could arise from their transformed state, we examined their phenotype regarding their capacity to grow in an anchorage-independent manner. Stat3C-expressing cells were suspended in soft agarose with HC11-Stat3C cells as a positive control, and their colony-forming ability was examined. As shown in Figure 4, HC11-Stat3C cells formed colonies in soft agarose. However, the colony-forming ability of MSCV-Stat3C or lenti-Stat3C clones was not higher compared to the parental $\mathrm{HC} 11$, or cells expressing GFP alone (13). Therefore, despite the fact that the Stat3C levels expressed in the MSCV-Stat3C-a and b clones tested were sufficient to reduce differentiation to undetectable levels, they were not able to promote anchorage-independent proliferation (Figure 4). Taken together, the above results demonstrate that Stat3C is unable to substitute for the E-cadherin/Rac-mediated differentiation signal. On the contrary, Stat3C blocks differentiation. Moreover, Stat3C at very low levels that is unable to fully transform $\mathrm{HC} 11$ cells, is still able to block their differentiation, indicating that this ability is not derived from, and can be clearly uncoupled, from its transforming effect.

\section{Discussion}

Mammary epithelial cell differentiation depends on the coordination of a complex array of extra- and intracellular signaling molecules. This work examined the role of Ecadherin/Stat3 signalling on HC11 mammary epithelial cell differentiation as opposed to neoplastic conversion, in an attempt to uncover the consequences of dysregulation of this pathway upon cell fate.

Stat3 activity is required for HC11 mammary epithelial cell differentiation. Since confluence, which dramatically increases levels of Stat3-ptyr705 (10), is a known prerequisite for epithelial cell differentiation (2), we explored the Stat 3 activity requirement for the differentiation of $\mathrm{HC} 11$ cells. Our results demonstrated an increase in Stat 3 activity with HIP treatment. Indeed, Stat 3 has been identified as an effector of the prolactin receptor $(26,27)$, therefore prolactin may be the element responsible for the observed Stat3ptyr705 elevation in HIP treated cells.

Figure 3. Constitutively active, Stat $3 \mathrm{C}$ reduces $\mathrm{HC} 11$ cell differentiation. (A) MSCV-Stat3C expression eliminates HC11 cell differentiation: HC11 cells expressing Stat $3 C$ with the MSCV retroviral vector (clones MSCVStat $3 C$ - $a$ and MSCV-Stat $3 C-b$ ), as well as the parental HC11 cells, were grown in the absence of EGF for 24 hours, then they were induced to differentiate with HIP addition for the indicated number of days (lanes 3-6, 9-12 and 15-18). Cells treated with medium lacking EGF (NE) served as controls (lanes 1-2, 7-8, and 13-14). Detergent cell extracts were probed for $\beta$-casein, total-Stat3, or $\beta$-actin as a loading control, as indicated. Representative of 3 experiments. Numbers at the right refer to molecular weight markers. Note the lack of $\beta$-casein expression in MSCV-Stat3C-a or MSCV-Stat3C-b cells compared to the parental HC11 (lanes 9-12, 15-18 versus 3-6). (B) Lentiviral Stat3C-GFP expression reduces $\mathrm{HC} 11$ cell differentiation: $\mathrm{HC} 11$ cells expressing Stat $3 C$ with a lentiviral vector (clones Stat $3 C$-c and Stat $3 C-d$ ), as well as parental HC11 cells, were grown in the absence of EGF for 24 hours, and were then induced to differentiate with HIP addition for the indicated number of days. Detergent cell extracts were probed for $\beta$-casein, total Stat3, or $\beta$-actin as a loading control, as indicated. Numbers at the right refer to molecular weight markers. Representative of 3 experiments. Note the reduction of $\beta$-casein expression in HC11Stat $3 C$ cells compared to the parental HC11 (lanes 5-8, 9-12 versus 14). (C) Stat3 transcriptional activity following Stat3C expression: i) Upper panel: HC11 cells, before or following Stat3C expression as above, were transfected with the Stat3-dependent pLucTKS3 and the Stat3-independent pRLSRE reporters at a confluence of 30\%. 48 hours later, firefly (ם) or Renilla $(\square)$ luciferase activities were determined in detergent cell extracts (23). Values shown represent luciferase units expressed as a percentage of the highest value obtained, means \pm SEM of at least 3 experiments, each performed in triplicate. ii) Lower panel: Same cells as above, probed for $\beta$-casein to assess differentiation. 
A

MSCV Stat3C

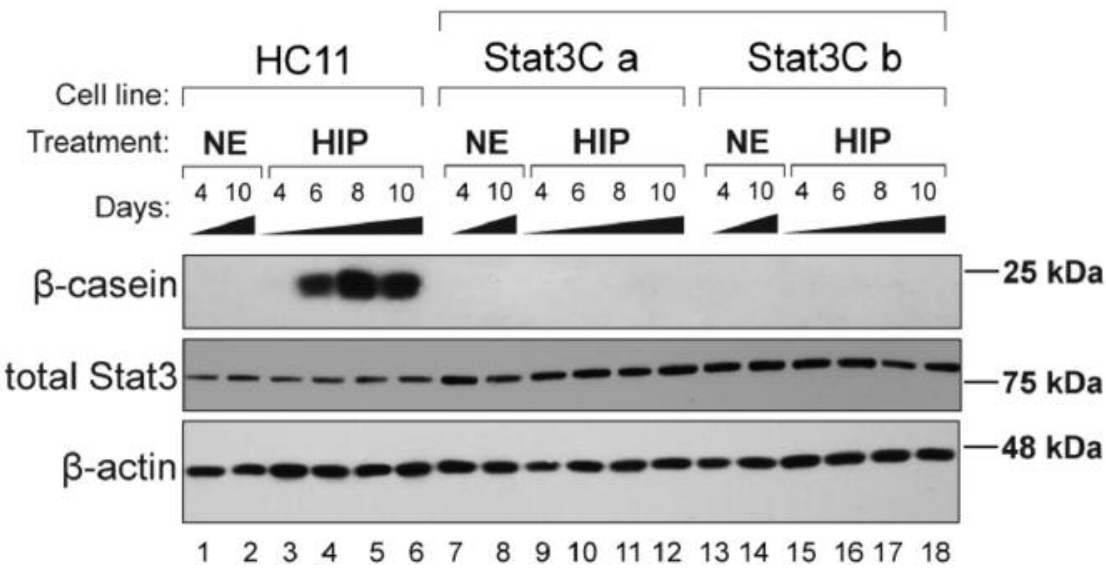

B
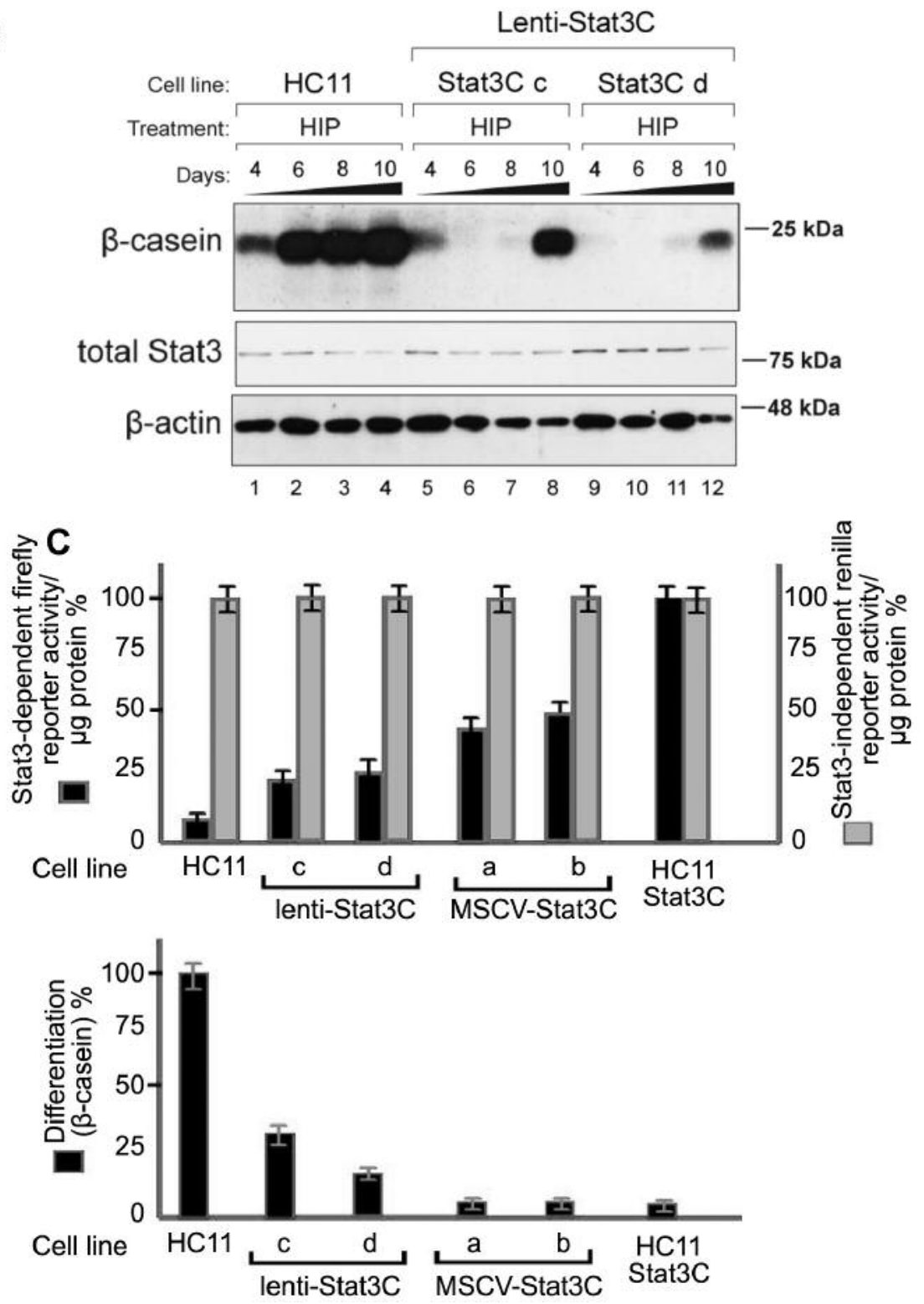

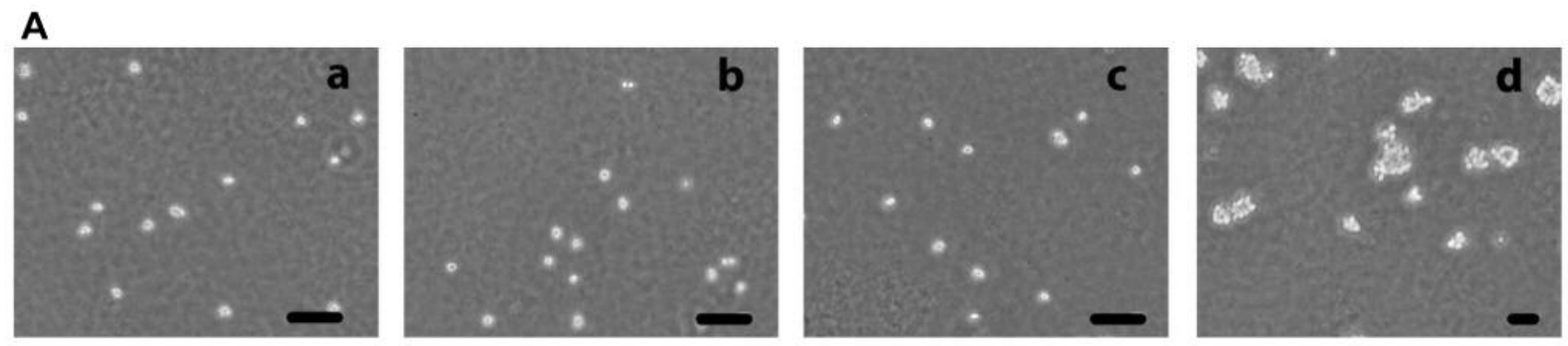

B

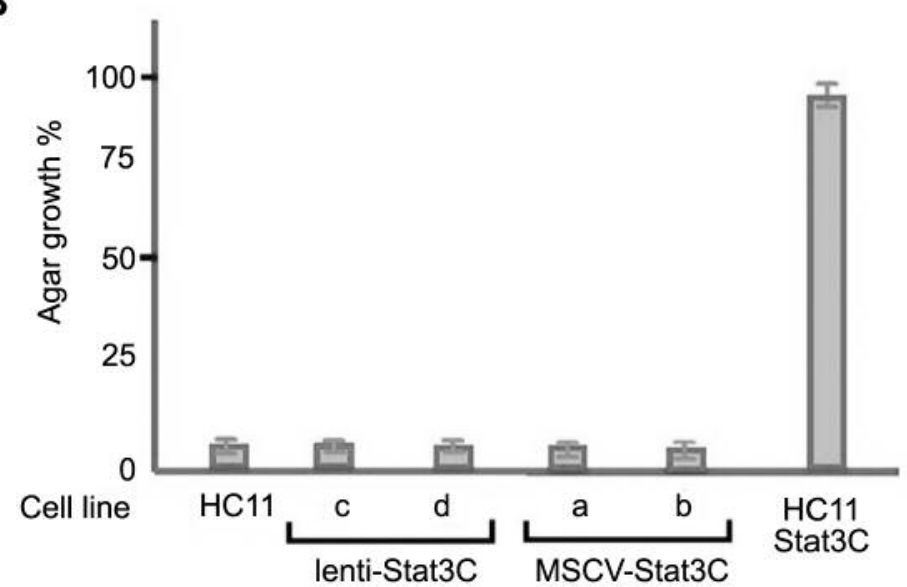

Figure 4. Anchorage-dependence of non-differentiating Stat3C-expressing cells. (A) MSCV-Stat3C-a (b), lenti-Stat3C-c (c) cells, HC11-Stat3C $(d(10))$, or parental HC11 (a) cells plated on soft agarose and photographed 20 days later under phase-contrast illumination. Scale bars: $100 \mu$ m. Representative of 3 experiments. (B) Agar growth quantitation. Colonies were counted and growth was expressed as a \% of total cell count. Averages of 3 experiments \pm SEM.

The surge in Stat3-ptyr705 levels in differentiation-induced HC11 cells prompted us to assess whether Stat3 activity might actually be required for HC11 differentiation. In fact, Stat 3 inhibition by just $\sim 15 \%$ and for just $24 \mathrm{~h}$ prior to the induction of differentiation eliminated their differentiation, pointing to a Stat3 requirement in this process. However, Stat 3 inhibition on day 5 had a less profound effect. This result demonstrates that Stat3 activity is vital for a narrow window of time, during early stages of differentiation, while after this point Stat3 activity appears to be dispensable.

Stat 3 has been demonstrated to provide a potent survival signal, which is especially important at confluence and later time points $[(10,28)$, reviewed in $(25)]$. However, the fact that HC11 differentiation is sensitive to the timing of CPA7 treatment, points to alternative mechanisms. In fact, Stat5, another member of the family, is a well-documented regulator of lactogenic differentiation and positively regulates the $\beta$-casein promoter (27). As Stat 3 and Stat5 have been shown to form heterodimers (29) and are active in this system, this could suggest a way in which Stat3, through its interaction with Stat5, might transcriptionally up-regulate the $\beta$-casein promoter and therefore contribute to $\beta$-casein expression and differentiation.

Expression of constitutively active, Stat $3 C$ reduces mammary epithelial cell differentiation. Although Stat3 activity is required for $\mathrm{HC} 11$ cell differentiation, our results indicate that overexpression of Stat3C was neither able to drive the expression of the differentiation marker, $\beta$-casein, in uninduced cells, nor to potentiate the differentiation signal in HIP-induced cells. On the contrary, all HC11-Stat3C clones either display a markedly reduced expression of $\beta$ casein or they fail to differentiate altogether.

Since Stat3C can act as an oncogene, and a number of oncogenes are known to block differentiation, we examined whether this inhibition of differentiation could be attributable to the activation of oncogenic targets that may be dominant over the pro-differentiation signals. However, our results revealed an absence of measurable growth in agarose. This could be due to the fact that the Stat3C levels used in the clones were not sufficient for transformation, despite the fact that they suppressed differentiation. In any event, the inability of the cells 
to grow in the absence of anchorage suggests that the block of differentiation by Stat3C is not immediately attributable to its transforming potential. Still, the fact that no increase in $\beta$-casein expression was observed even at very low levels points to differences in the effectors of Stat $3 \mathrm{C}$ versus $\mathrm{Rac}^{\mathrm{V} 12}$, which promote differentiation. It is conceivable that even lower Stat3C levels might have increased differentiation, as in the case of $\mathrm{Rac}^{\mathrm{V} 12}$, however, no increase in the differentiation was ever observed, even when Stat3C levels were barely detectable.

We recently demonstrated that $\mathrm{Rac}^{\mathrm{V} 12}$ expression in $\mathrm{HC} 11$ cells is able to down-regulate E-cadherin, even at levels that are insufficient to fully suppress differentiation (13). Since Stat3 is a downstream effector of Rac in HC11 cells (10), it might be expected that Stat3C, at levels sufficient to block differentiation, might reduce E-cadherin levels. However, in sharp contrast to cells expressing even low amounts of $\mathrm{Rac}^{\mathrm{V} 12}$, Stat3C was found to be unable to reduce E-cadherin levels even when expressed to levels that are sufficiently high as to eliminate differentiation (not shown). Therefore, it appears that $\mathrm{Rac}^{\mathrm{V} 12}$ is employing a different pathway(s) from Stat3C to block differentiation, despite the fact that Stat3 is one of the downstream effectors of Rac.

The strength of the E-cadherin/Stat3 signalling pathway is a key determinant of the outcome of the differentiation process in breast epithelial cells, with Stat 3 activity being critically required for differentiation. However, overexpression of the activated form, Stat3C, rather than promoting, it blocks differentiation, even when expressed at low levels, and in the absence of full neoplastic conversion. Whether the same model holds true in other differentiation systems known to require cell to cell adhesion, such as adipocytes and myoblasts (30), remains to be seen.

\section{Conflicts of Interest}

The Authors declare that there are no conflicts of interest.

\section{Authors' Contributions}

MN, MG, ZT, RA, JC, and VH performed most experiments under the supervision of BE, PG, and LR. BE provided ideas and supervision. PG provided Stat3 inhibitors and funding. LR conceived the project, provided funding, and supervised throughout.

\section{Acknowledgements}

The Authors would like to thank Dr Daniel Link for a gift of the MSCV-Stat3C retroviral vector and Dr. Linzhao Chang for the lentiviral vector. Some of the data presented in this study constituted parts of the Ph.D. thesis of JC (Queen's University, 2013).

The financial assistance of the Natural Sciences and Engineering Research Council of Canada (NSERC), the Canadian Institutes of Health Research (CIHR), the Canadian Breast Cancer Foundation (CBCF, Ontario Chapter), the Canadian Breast Cancer Research Alliance, the Ontario Centres of Excellence, the Breast Cancer Action
Kingston (BCAK) and the Clare Nelson bequest fund through grants to LR is gratefully acknowledged. PTG was supported by a Canada Research Chair, Canadian Foundation for Innovation, CIHR, NSERC and Canadian Cancer Society. BE received grant support from CIHR, CBCF, BCAK and Cancer Research Society Inc. MN was supported by a studentship from the Terry Fox Training Program in Transdisciplinary Cancer Research, a Graduate award (QGA), and a Dean's Award from Queen's University. JC was supported by a Terry Fox Foundation Training Award in Transdisciplinary Cancer Research in partnership with the Canadian Institutes of Health Research, and a QGA. MG was supported by postdoctoral fellowships from the US Army Breast Cancer Program, the Ministry of Research and Innovation of the Province of Ontario and the Advisory Research Committee of Queen's University. RA was supported by a Canada Graduate Scholarships Doctoral award from CIHR, the Ontario Women's Health Scholars Award from the Ontario Council on Graduate Studies and a QGA. ZT was supported by an NSERC CGS$\mathrm{M}$ and Queen's Graduate Awards.

\section{References}

1 Humphreys RC and Rosen JM: Stably transfected hc11 cells provide an in vitro and in vivo model system for studying wnt gene function. Cell Growth Differ 8(8): 839-849, 1997. PMID: 9269893.

2 Merlo GR, Graus-Porta D, Cella N, Marte BM, Taverna D and Hynes NE: Growth, differentiation and survival of hc11 mammary epithelial cells: Diverse effects of receptor tyrosine kinase-activating peptide growth factors. Eur J Cell Biol 70(2): 97-105, 1996. PMID: 8793381.

3 Turkson J, Bowman T, Garcia R, Caldenhoven E, de Groot RP and Jove R: Stat3 activation by src induces specific gene regulation and is required for cell transformation. Mol Cell Biol 18(5): 2545-2552, 1998. PMID: 956687.

4 Yu H, Pardoll D and Jove R: Stats in cancer inflammation and immunity: A leading role for stat3. Nat Rev Cancer 9(11): 798809, 2009. PMID: 19851315. DOI: $10.1038 / \mathrm{nrc} 2734$

5 Liu Y, Huang J, Li W, Chen Y, Liu X and Wang J: Meta-analysis of stat 3 and phospho-stat 3 expression and survival of patients with breast cancer. Oncotarget 9(16): 13060-13067, 2018. PMID: 29560131. DOI: 10.18632/oncotarget.23962

6 Banerjee $\mathrm{K}$ and Resat $\mathrm{H}$ : Constitutive activation of stat 3 in breast cancer cells: A review. Int J Cancer 138(11): 2570-2578, 2016. PMID: 26559373. DOI: $10.1002 / \mathrm{ijc} .29923$

7 Geletu M, Arulanandam R, Greer S, Trotman-Grant A, Tomai E and Raptis L: Stat3 is a positive regulator of gap junctional intercellular communication in cultured, human lung carcinoma cells. BMC Cancer 12: 605, 2012. PMID: 23244248. DOI: 10.1186/1471-2407-12-605

8 Vultur A, Arulanandam R, Turkson J, Niu G, Jove R and Raptis L: Stat 3 is required for full neoplastic transformation by the simian virus 40 large tumor antigen. Mol Biol Cell 16: 38323846, 2005. PMID: 15917293. DOI: 10.1091/mbc.E04-12-1104

9 Bromberg JF, Wrzeszczynska MH, Devgan G, Zhao Y, Pestell RG, Albanese C and Darnell JE Jr.: Stat3 as an oncogene. Cell 98(3): 295-303, 1999. PMID: 10458605.

10 Arulanandam R, Vultur A, Cao J, Carefoot E, Truesdell P, Elliott B, Larue L, Feracci $\mathrm{H}$ and Raptis L: Cadherin-cadherin engagement promotes survival via rac/cdc42 and stat3. Molecular Cancer Research 17: 1310-1327, 2009. PMID: 19671682. DOI: 10.1158/1541-7786.MCR-08-0469 
11 Geletu M, Arulanandam R, Chevalier S, Saez B, Larue L, Feracci $\mathrm{H}$ and Raptis L: Classical cadherins control survival through the gp130/stat3 axis. BBA-Mol Cell Res 1833: 1947-1959, 2013. PMID: 23541910. DOI: 10.1016/j.bbamcr. 2013. 03.014

12 Arulanandam R, Geletu M, Feracci H and Raptis L: Racv12 requires gp130 for stat3 activation, cell proliferation and migration. Exp Cell Res 316: 875-886, 2010. PMID: 19852956. DOI: $10.1016 /$ j.yexcr.2009.10.017

13 Niit M, Arulanandam R, Cass J, Geletu M, Hoskin V, Cote G, Gunning P, Elliott B and Raptis L: Regulation of hc11 mouse breast epithelial cell differentiation by the e-cadherin/rac axis. Exp Cell Res 361(1): 112-125, 2017. PMID: 29031557. DOI: 10.1016/j.yexcr.2017.10.008

14 Turkson J, Zhang S, Palmer J, Kay H, Stanko J, Mora LB, Sebti $\mathrm{S}, \mathrm{Yu} \mathrm{H}$ and Jove R: Inhibition of constitutive signal transducer and activator of transcription 3 activation by novel platinum complexes with potent antitumor activity. Mol Cancer Ther 3(12): 1533-1542, 2004. PMID: 15634646.

15 Littlefield SL, Baird MC, Anagnostopoulou A and Raptis L: Synthesis, characterization and stat 3 inhibitory properties of the prototypical platinum(iv) anticancer drug, [ptcl3(no2)(nh3)2] (cpa-7). Inorg Chem 47(7): 2798-2804, 2008. PMID: 18269242. DOI: $10.1021 /$ ic $702057 \mathrm{q}$

16 Geletu M, Mohan R, Arulanandam R, Berger-Becvar A, Nabi IR, Gunning PT and Raptis L: Reciprocal regulation of the cadherin$11 /$ stat 3 axis by caveolin- 1 in mouse fibroblasts and lung carcinoma cells. Biochim Biophys Acta 1865: 794-802, 2018. PMID: 29458077. DOI: 10.1016/j.bbamcr.2018.02.004

17 Haftchenary S, Luchman HA, Jouk AO, Veloso AJ, Page BD, Cheng XR, Dawson SS, Grinshtein N, Shahani VM, Kerman K, Kaplan DR, Griffin C, Aman AM, Al-Awar R, Weiss S and Gunning PT: Potent targeting of the stat 3 protein in brain cancer stem cells: A promising route for treating glioblastoma. ACS Med Chem Lett 4(11): 1102-1107, 2013. PMID: 24900612. DOI: $10.1021 / \mathrm{ml} 4003138$

18 Cass J: Novel stat3 and stat5 pathways in epithelial cell differentiation. Ph.D. Thesis, Queen's University, 2013. Available from: http://hdl.handle.net/1974/8542

19 Siddiquee K, Zhang S, Guida WC, Blaskovich MA, Greedy B, Lawrence HR, Yip ML, Jove R, McLaughlin MM, Lawrence NJ, Sebti SM and Turkson J: Selective chemical probe inhibitor of stat3, identified through structure-based virtual screening, induces antitumor activity. Proc Natl Acad Sci USA 104(18): 7391-7396, 2007. PMID: 17463090. DOI: 10.1073/pnas.06097 57104

20 McLemore ML, Grewal S, Liu F, Archambault A, PoursineLaurent J, Haug J and Link DC: Stat-3 activation is required for normal g-csf-dependent proliferation and granulocytic differentiation. Immunity 14(2): 193-204, 2001. PMID: 11239451.

21 Hillion J, Dhara S, Sumter TF, Mukherjee M, Di Cello F, Belton A, Turkson J, Jaganathan S, Cheng L, Ye Z, Jove R, Aplan P, Lin YW, Wertzler K, Reeves R, Elbahlouh O, Kowalski J, Bhattacharya $\mathrm{R}$ and Resar LM: The high-mobility group a1a/signal transducer and activator of transcription-3 axis: An achilles heel for hematopoietic malignancies? Cancer Res 68: 10121-10127, 2008. PMID: 19074878. DOI: 10.1158/00085472.CAN-08-2121
22 Greer S, Honeywell R, Geletu M, Arulanandam R and Raptis L: Housekeeping gene products; levels may change with confluence of cultured cells. J Immunol Methods 355: 76-79, 2010. PMID: 20171969. DOI: 10.1016/j.jim.2010.02.006

23 Vultur A, Cao J, Arulanandam R, Turkson J, Jove R, Greer P, Craig A, Elliott BE and Raptis L: Cell to cell adhesion modulates stat 3 activity in normal and breast carcinoma cells. Oncogene 23: 2600-2616, 2004. PMID: 15007380. DOI: 10.1038/sj.onc. 1207378

24 Raptis L, Arulanandam R, Vultur A, Geletu M, Chevalier S and Feracci H: Beyond structure, to survival: Stat 3 activation by cadherin engagement. Biochem Cell Biol 87: 835-843, 2009. PMID: 19935869. DOI: 10.1139/009-061

25 Geletu M, Guy S, Arulanandam R, Feracci H and Raptis L: Engaged for survival; from cadherin ligation to stat 3 activation. Jaks-Stat 2: e27363-27361-e27363-27368， 2013. PMID: 24470979. DOI: $10.4161 /$ jkst.27363

26 DaSilva L, Rui H, Erwin RA, Howard OM, Kirken RA, Malabarba MG, Hackett RH, Larner AC and Farrar WL: Prolactin recruits stat 1 , stat 3 and stat 5 independent of conserved receptor tyrosines tyr402, tyr479, tyr515 and tyr580. Mol Cell Endocrinol 117(2): 131-140, 1996. PMID: 8737372.

27 Hennighausen L, Robinson GW, Wagner KU and Liu X: Developing a mammary gland is a stat affair. J Mammary Gland Biol Neoplasia 2(4): 365-372, 1997. PMID: 10935024.

28 Anagnostopoulou A, Vultur A, Arulanandam R, Cao J, Turkson J, Jove R, Kim JS, Glenn M, Hamilton AD and Raptis L: Differential effects of stat 3 inhibition in sparse vs confluent normal and breast cancer cells. Cancer Lett 242: 120-132, 2006. PMID: 16377083. DOI: 10.1016/j.canlet.2005.10.047

29 Delgoffe GM and Vignali DA: Stat heterodimers in immunity: A mixed message or a unique signal? JAKSTAT 2(1): e23060, 2013. PMID: 24058793. DOI: $10.4161 /$ jkst.23060

30 Ostrovidov S, Hosseini V, Ahadian S, Fujie T, Parthiban SP, Ramalingam M, Bae H, Kaji H and Khademhosseini A: Skeletal muscle tissue engineering: Methods to form skeletal myotubes and their applications. Tissue Eng Part B Rev 20(5): 403-436, 2014. PMID: 24320971. DOI: 10.1089/ten.TEB.2013.0534 